Volume (4) No. (1) 2021

دور تكنولوجيا التعليم في مواجهة المشكلات الأكاديمية الناجمة عن انتشار جائحة فيروس كورونا لدي طلاب المرحلة الثانوية

حسن علي مهدي الأمير 
دور تكنولوجيا التعليم في مواجهة المشكلات الأكاديمية الناجمة عن انتشار جائحة فيروس

كورونا لدي طلاب المرحلة الثانوية

$$
\text { معلم رياضيات، إدارة تعليم صبيا، السعودية مهدي الأمير }
$$

hassanalameer15@gmail.com

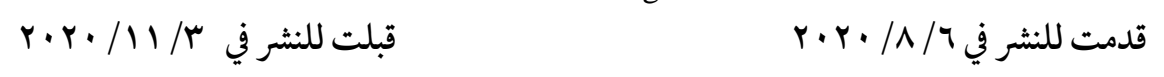

ملخص: هدفت هذه الدراسة إلي: تعرف دور تكنولوجيا التعليم في مواجهة المشكلات الأكاديمية

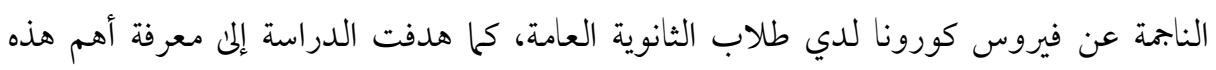

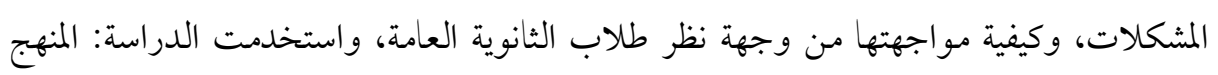

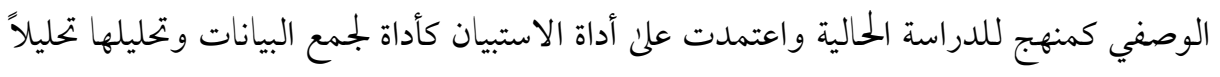

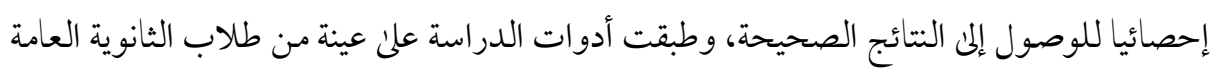

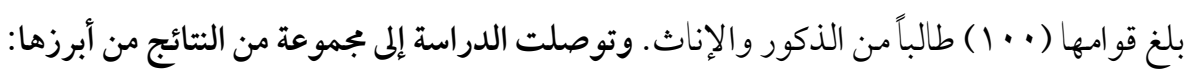

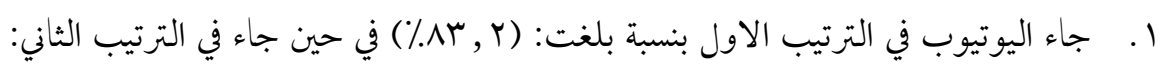

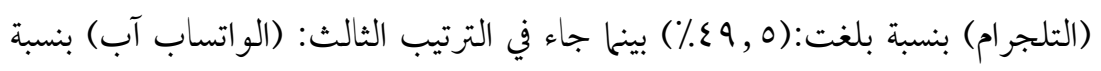

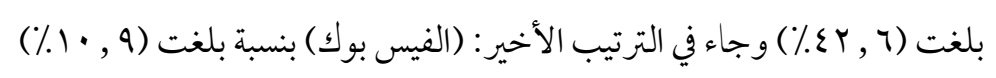

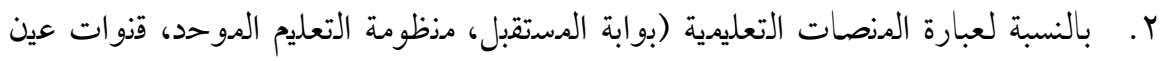

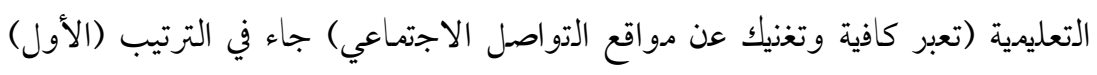

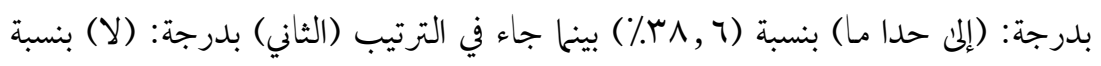

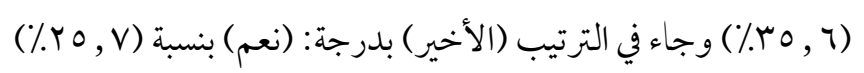

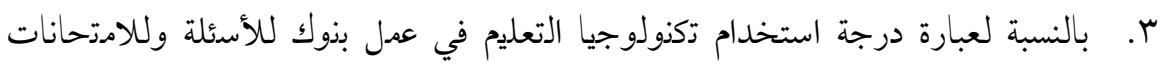

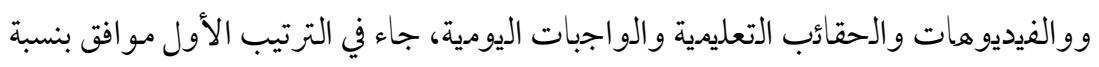

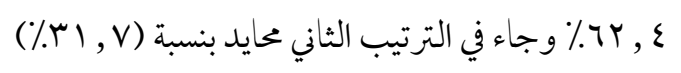

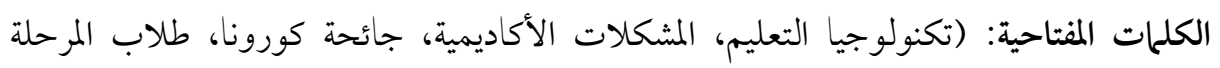

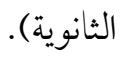




\section{The role of educational technology in facing the academic problems resulting from the Coronavirus (Covid - 19) pandemic among secondary school students}

Hassan Ali AlAmer

Mathematics Teacher, Sabya Dirctorate of Education, KSA hassanalameer15@gmail.com

Received in 6th August 2020

Accepted in 3rd November 2020

Abstract: This study aimed to: identify the role of educational technology in facing academic problems caused by the Corona virus among high school students. The study also aimed to know the most important of these problems, and how to address them from the viewpoint of high school students, and the study used the descriptive approach as a curriculum for the current study and relied The questionnaire tool as a tool for collecting data and analyzing it statistically to reach the correct results. The study tools were applied to a sample of high school students of (100) male and female students.

The study reached a set of results, the most important of which are:

1. YouTube came in first place with a percentage of $(83.2 \%)$, while it came in the second order: (Telegram) with a rate of (49.5\%), while it came in the third order: (WhatsApp August) with a rate of (42.6\%) and came in the ranking The last: (Facebook) by (10.9\%).

2. With regard to the term educational platforms (the portal of the future, the unified education system, Ain educational channels (express enough and exempt from social media sites) came in (first) ranking with a degree (to some extent) with a rate of (38.6\%) while it came in the second (With a degree: (No) by (35.6\%), and it came in (last) ranking, in part: (Yes) by $(25.7 \%)$.

3. With regard to the degree of the degree of use of education technology in the work of banks for questions, exams, videos, educational bags and daily assignments, it came first in terms of approval by $62.4 \%$ and in the second order was neutral $(31.7 \%)$.

Keywords: educational technology, academic problems, Corona pandemic, high school students). 
باتت الابتكارات العلمية والتقنية علامة ميزة للقرن الواحد و العشرين، إذ أصبح من الصعب

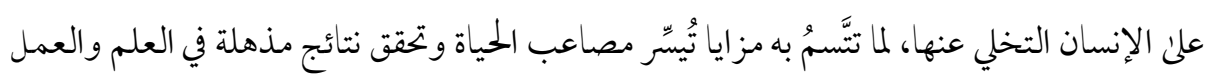

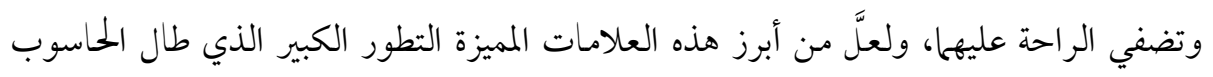

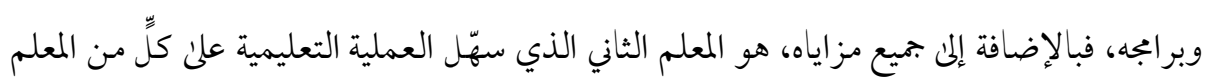
و المتعلم، ببرامجه و ألعابه المتنوعة.

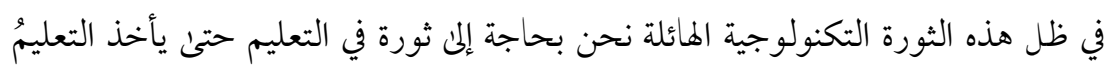
شكلَ المنظومة التعليمية، ونستبدلُ بذلك الثوب القديم ثوباً جديداً، ليس في درجة جاذبيته الشكلية فقط، ولكن فيما يكمن وراءهء، أي في جوهر المنظومة التعليمية بمكوناتها المختلفة، حتى نساير عصر ثورة المعلومات، ولذلك أصبح من الضروريِّ استخدامُ التكنولوجيا الحديثة القائمة علن تكنولوجيا المعلومات، وما يرتبط بها من حاسباتٍ وشبكات نقل المعلومات، لنتقل من حالة التعليم الجامد إلى

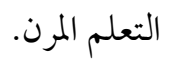
وبشكل محدد، فإن إشكالية تجويد التعليم، ومحاو لات رفع المستوى التعليمي للطلاب، والتي تمثل هدفًا أساسيًا للنظام التعليمي قد تعني ضرورة الاهتحام بمدخلات العملية التعليمية ذات الصلة

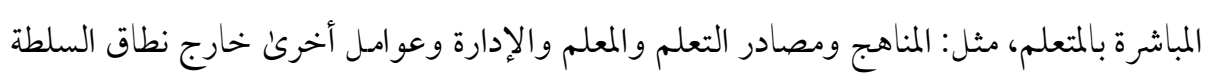
التعليمية مثل النظم الاجتماعية والاقتصادية السائدة، والتي قد تفرض توجهات ضاغطة وربها عكسية لمسارات الحاجة لتطوير التعليم. وقد يبدو الأمر أكثر تعقيدًا، عندما نفترض أن ثمة عوامل عديدة تكمن خلف المشكلات التعليمية التي تطل برأسها علينا من حين لأخر، أو مازالت طافية علن سطح الواقع التعليمي، وله تختف بعد، أو نفشل في احتو ائها بشكل فعلي. فالمناهج الدراسية باعتبارها واحدة، من أكثر مدخلات العملية التعليمية أهمية، والتي قد بدان يعلق عليها البعض كثيرًا من جوانب الفشل، قد تكون مناسبة، أو متطورة، وليس فيها ما يدعو 
للقلق، لكن الاختلالات الناجمة قد تكون راجعة لتراخي المعلمين وضعف كفاءتهم وتدني برامجج إعدادهم، وربها تتأثر الجودة التعليمية بضعف عمليات الإرشاد والتوجيه في المدارس، أو تدني في كفاءة الإدارة المدرسية، أو غير ذلك من عناصر كثيرة مؤثرة بطريقة مباشرة، أو غير مباشرة في المستوكئ

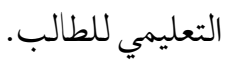

مشكلة الدراسة: إن الاهتحام الدائم والمستمر الذئ تسعي إليه المؤسسات والهيئات التربوية و التعليمية يعنى عناية فائقة بالنهوض بالعملية التربوية والتعليمية إلى أعلان مستوى يمكن الوصول

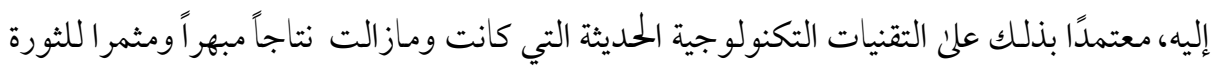
التكنولوجية الحديثة الشاملة؛ حيث إنها مستمرة في الصعود الدائم والتغلغل الذئ لا ينقطع في اختراق شتى المجالات والتطبيقات المعاصرة، والتابلت أحد تلك التقنيات التكنولوجية الحديثة الذئ يتمتع بعدد من المميزات، مثل: سهولة النقل، وخفة الوزن، وقلة التكلفة.

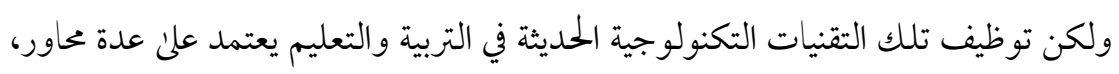
منها المتعلم، وهو الطالب الذئ تسعئ المؤسسات والهيئات التربوية والتعليمية إلى تزويده بالمعرفة و التدريب وتنمية قدراته ومهارته من خال الاستخدامات المتنوعة والتطبيقات الهائلة للمستحدثات التكنولوجية وربطها بالمواد العلمية المطلوب إمداده بها، بحيث يستطيع الطالب تحقيق أكبر قدر من التحصيل والاستيعاب بكل سهولة ويسر لهذه المو اد العلمية المطروحة وتحقيق الفهم العميق والدقيق من خال العروض المقدمة والأشكال المستحدثة لتلك التطبيقات التكنولوجية، إضافة إلى تأسيس

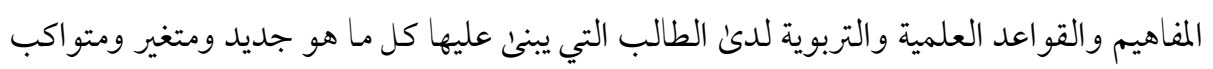

$$
\text { مع المتطورات العصرية الحديثة(الحسن، } 0 \text {. • ب، ص: 00 ). }
$$

من أجل ذلك، عنيت كافة الوسائل التعليمية والاستراتيجيات الحديثة والأساليب التربوية والتعليمية المتنوعة لترتقي بالمستون العلمي والتربوي لبناء جيل من الطاب لديه الوعي بأهمية

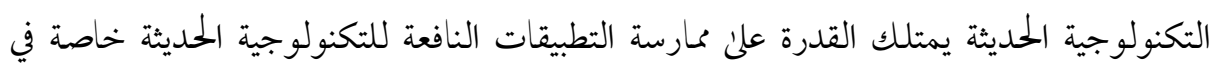
الاتجاهات التعليمية والتربوية.

\section{http://dx.doi.org/10.29009/ijres.4.1.7}


ولذا تسعي الدراسة الحالية إلى معرفة دور تكنولوجيا التعليم في مواجهة المشكلات الأكاديمية

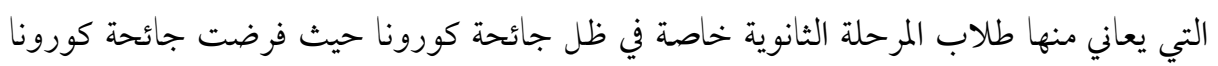

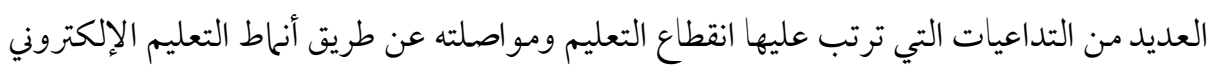

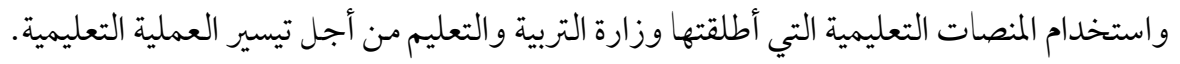

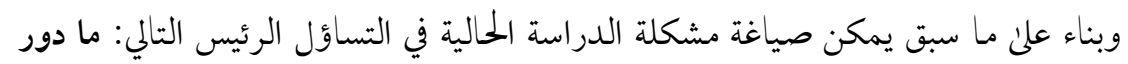
تكنولوجيا التعليم في مواجهة المشكلات الأكاديمية الناجم عن جائحة فيروس كورونا لدي طلاب

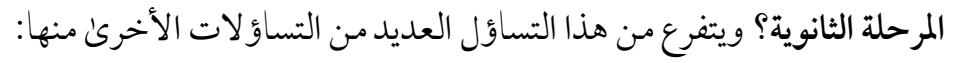
ا. ـ مـا المشكلات الأكاديمية التي تواجه طلاب المرحلة الثانوية؟

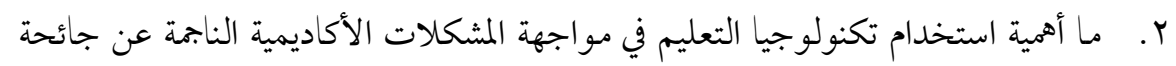

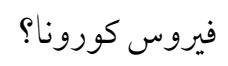

r. ما أهم أنماط التكنولوجيا التي يمكن استخدامها للتغلب علن المشكلات الأكاديمية التي

$$
\text { أهمية الدراسة: وكانت كالتالي: }
$$

ا. قد تفيد الدراسة القائمين علن أمور التربية والتعليم من معلمين ومدراء وأولياء أمور

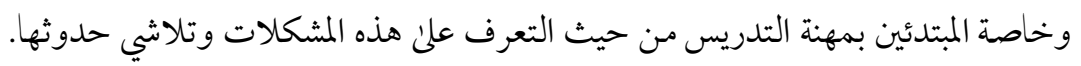

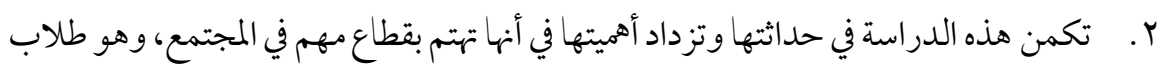

$$
\text { المرحلة الثانوية حيث تعدمر حلة انتقالية هامة في مستقبل. }
$$

r. تعني هذه الدراسة بتقديم العديدمن التوجيهات للقائمين والمسؤولين علن العملية التعليمية

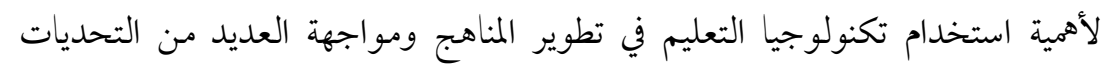

$$
\begin{aligned}
& \text { والعقبات والمشكلات الأكاديمية التي تواجه الطلاب في هذه المرحلة. } \\
& \text { أهداف الدراسة: تسعي الدراسة الحالية إلى تحقيق العديد من الأهداف ومنها: }
\end{aligned}
$$


1. تحديد دور التكنولوجيا والتقنيات الحديثة في تحسين ومو اجهة المشكلات الأكاديمية في ظل وجود جائحة كورونا.

r. تعرف أهم المشكلات الأكاديمية التي يعاني منها طلاب الثانوية العامة في ظل جائحة كورونا. r. الكشف عن أهم التقنيات الحديثة التي يمكن استخدامها للتغلب علن المشكلات الأكاديمية

$$
\text { في ظل جائحة كورونا. }
$$

ع. رصد أهم المقترحات التي تساهم في علاج المشكلات الأكاديمية التي يو اجهها الطلاب. حدود الدراسة: يمكن تحديد حدود الدراسة في الآتي:

ا. الحدود الموضوعية: اقتصرت الدراسة الحالية على دراسة دور تكنولوجيا التعليم في مواجهة

$$
\text { المشكلات الأكاديمية الناجمة عن جائحة فيروس كورونا. }
$$

r. الحدود المكانية: طبقت هذه الدراسة علن طلاب المرحلة الثانوية بإدارة تعليم صبيا، بالمملكة

$$
\text { العربية السعودية. }
$$

r. الحدود البشرية: طُبقت الدراسة على طلاب المرحلة الثانوية.

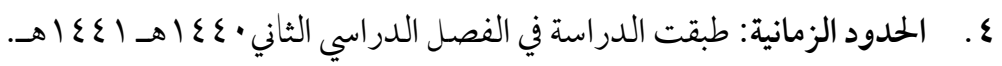
مصطلحات الدراسة :تستخدم الدراسة المصطلحات التالية:

1. مفهوم التكنولوجيا: لغة: تِكنولوجا: تِقنْيَّة؛ أسلوب الإنتاج أو حَصيلة المعرفة الفنيَّة، أو العلميّة

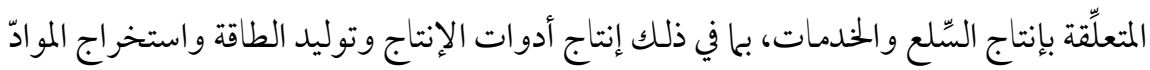
الأوّليّة ووسائل المو اصلات، وتُسمَّى أحيانًا العلم التطبيقيّ: تكنولوجيا الأسلحة، المعلومات، تكنولوجيا حيويَّة: (الأحياء) استخدام كائنات دقيقة وموادّ بيولوجيّة لإنجاز عمليّات صناعيّة

$$
\text { (معجم اللغة العربية المعاصرة، مادة: تِكنولوجا). }
$$

اصطلاحاً: قام "دونالد بيل" بتعريف مصطلح "التكنولوجيا" علن أنها: "العمل على تطويع خبرات

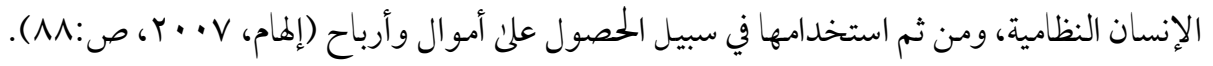


قام "جلبرت" بتعريف مصطلح "التكنولوجيا" كونها "جموعة التطبيقات المنظمة؛ والتي تهدف

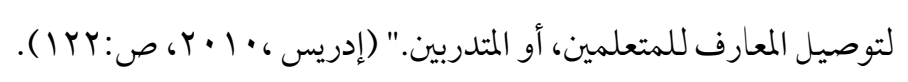

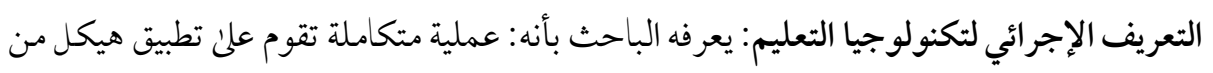

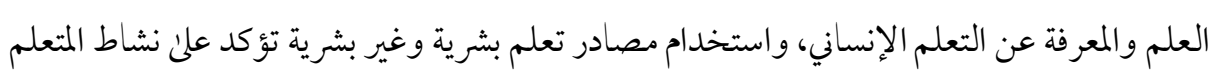

وفرديته بمنهجية أسلوب المنظومات لتحقيق الأهداف التعليمية والتوصل إلى تعلم أكثر فعالية.

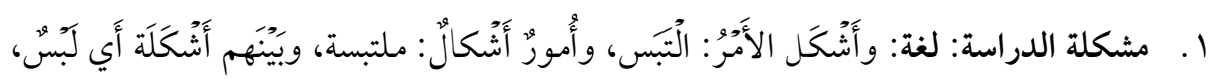

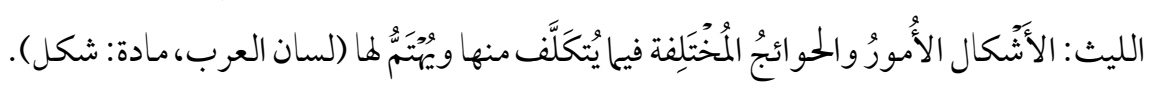

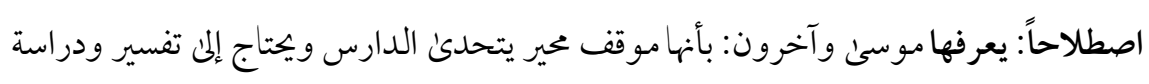

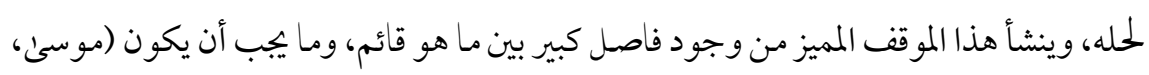

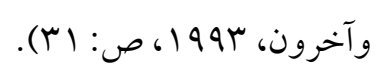

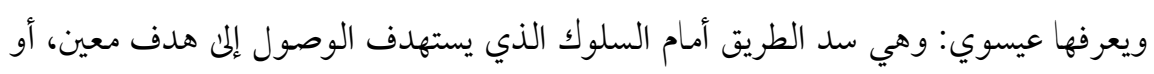

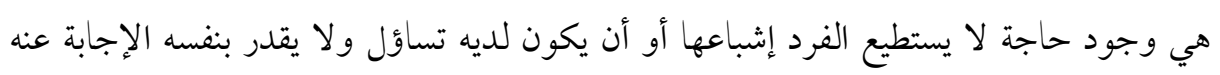

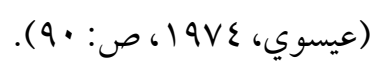

التعريف الإجرائي للمشكلة: يعرفها الباحث بأها: الصعوبات التي تواجه الطلبة وتعيق بلوغهم لحل

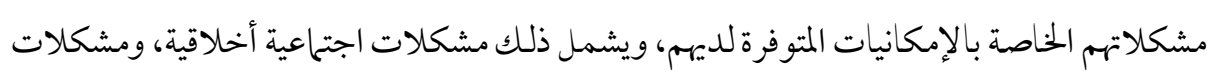
تعليمية، ومشكلات نفسية؛ تؤثر علن عملية التحصيل والتعامل مع المواد العلمية.

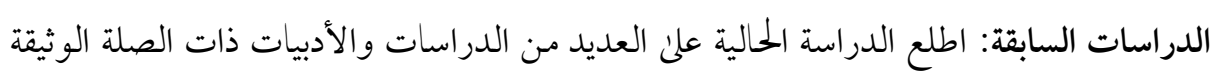
بموضوع الدراسة الحالية، وتم تناولها كالتالي:

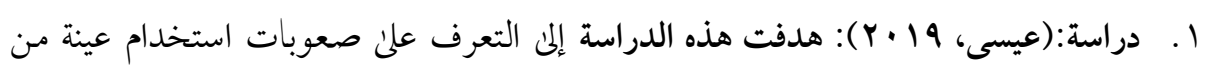

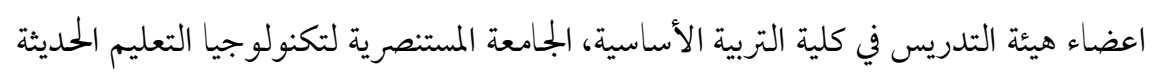

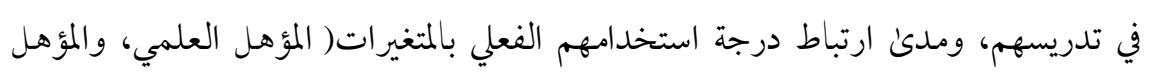
الأكاديمي، والتخصص، وسنوات الخبرة). 
وتوصلت الدراسة إلى عدد من النتائج، منها: وجود بعض العوائق التي تعيق استخدام اعضاء هيئة التدريس لتكنولوجيا التعليم في التدريس؛ كان من أهمها عدم توافر التجهيزات والبنى التحتية اللازمة، وبعضها مرتبط بضعف الدورات التدريبية في كيفية توظيف تكنولوجيا التعليم الحديثة في

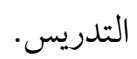

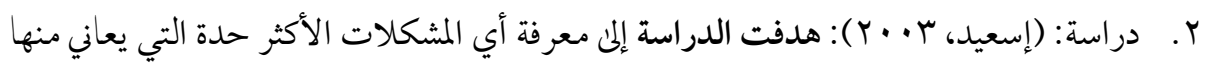
طلبة الصف الأول الثانوي (الحادي عشر) بمحافظة غزة، ومعرفة مدى' علاقة هذه المشكلات بمتغير الجنس والتخصص (أدبي - علمي) واستخدمت الدراسة :المنهج الوصفي التحليلي نظراً لمناسبته لأغراضِ الدراسة. وتوصلت الدراسة إلى عدد من النتائج، منها: وجود فروق ذات دلالة إحصائية يعزى لمتغير الجنس لصالح الإناث في بجال المشكلات النفسية (في حين أنها كانت لصالح الذكور في مجال ) المشكلات الجنسية، كما أظهرت النتائج وجود فروق دالة إحصائيا تعزىن لمتغير التخصص (أدبي -علمي) لصالح طلبة القسم الأدبي في مجالات المشكلات المتعلقة بالمشكلات (الاجتماعية الأخلاقية، النفسية، والجنسية) بينما لصالح القسم العلمي في بجال المشكلات المتعلقة بشغل أوقات الفراغ

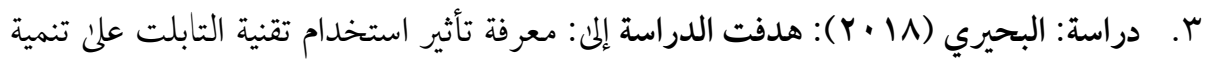
وتطوير المهارات التعليمية والتربوية لطاب التعليم الأساسي، واستخدمت الدراسة المنهج الوصفي في الدراسة. وتوصلت الدراسة إلى عدد من النتائج، منها: وجود الدور الإيجابي للتابلت في العملية (SPSS) باستخدام برنامج الحزم الاحصائية التعليمية والتربوية وبينت طبيعة العلاقة بين استخدامه في العملية التعليمية والتربوية وتنمية المهارات التعليمية والتربوية للطاب وانعكاسها علن التفاعلية.

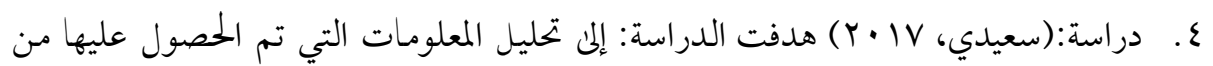
خلال أداوت جمع البيانات، وتوصلت الدراسة إلى عدد من النتائج، منها: أن أساتذة قسم اللغة

\section{http://dx.doi.org/10.29009/ijres.4.1.7}


والأدب العربي، مؤيدون وداعمون لتوجه الجامعة إلى توظيف تكنولوجيا التعليم ووسائلها

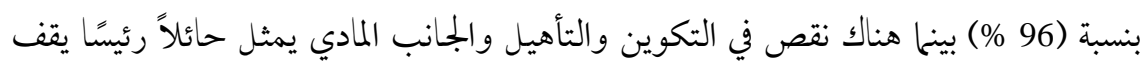

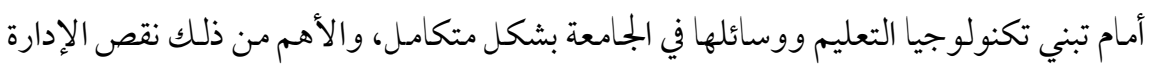
العليا لدعم دمج التكنولوجيا في التعليم. الإطار النظري للدراسة: تهيد: تؤدي التقنيات والوسائل التكنولوجية الحديثة في عصرنا الحلالي والمتميز بالثورة

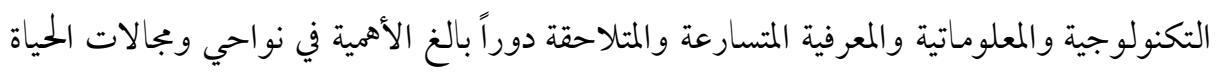
المختلفة، والمؤسسات والميئات والبيئات التربوية والتعليمية ليست ببعيدة، أو مستثناة من هذا الأمر. وقد أصبحت هذه التقنيات والوسائل التكنولوجية الحديثة مكوناً أساسياً من مكوناتها

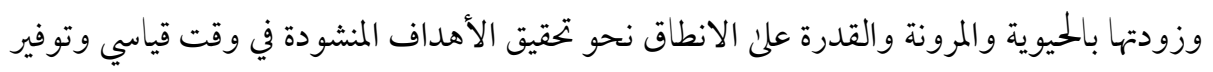

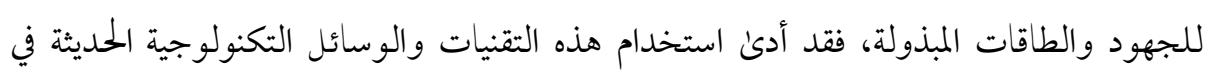

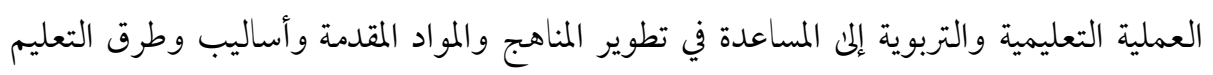
المثنوعة (عبد اللطيف، 10 • r، ص: 99 9 ).

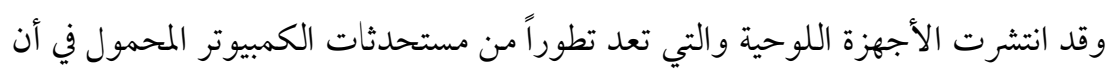

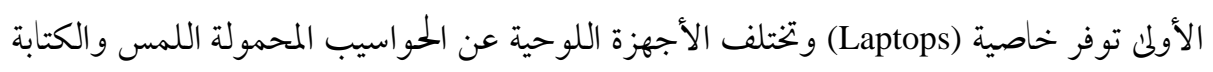

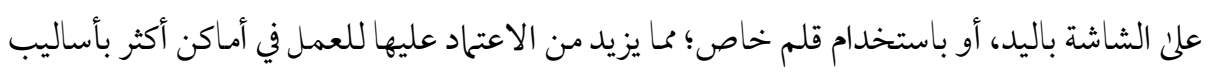
جديدة وفعالة، وجعلها أكثر قابلية للتنقل، ومتعددة الاستخدامات، حيث إنها تقدم الأداء الوظيفي

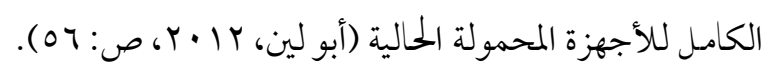

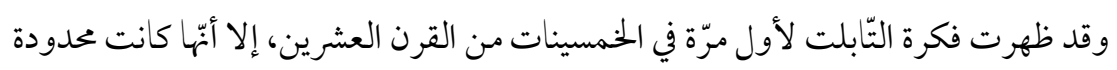

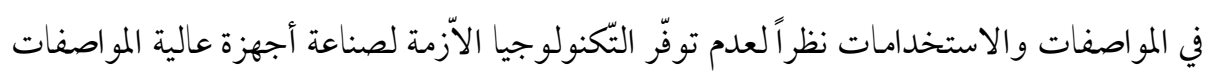

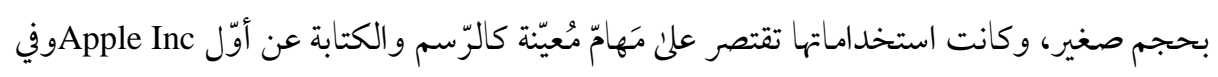


عام 2010 أعلنت شركة أبل iPad وسُمّي iPad1 إصدار من سلسلة أجهزة الآيباد (زيدان، 10 • Y، ص:00).

ثم حدثت تطورات هائلة للتابلت جعلته يتميز بالآتي( سالم، 2006): القدرة علن الاتصال بالإنترنت، وتصفح البريد الإلكتروني، وزيارة مو اقع التواصل الاجتحاعي في أي مكان عن طريق شبكات المحمول والواي فاي (الزهراني ،2011، ص: VV) و التواصل المباشر والفعال بين أطراف

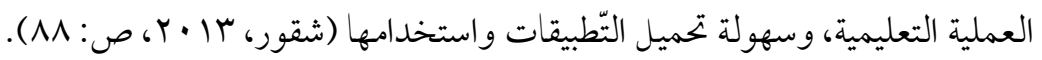
مفهوم تكنولوجيا التعليم: تكنولوجيا التعليم هو مصطلحٌ مكونٌ من جز أين: تكنولوجيا و التعليم، ويمكن بيان المقصود منها كالآتي: مصطلح تكنولوجيا: أصل مصطلح التكنولو جيا يوناني، و هو مشتقٌ من مقطعين، الأول: تكنو، بمعنى حرفة أو تطبيق، أوصنعة، والثاني: لوجي، ومعناه فن أو علم، ومعنى المصطلح كاملاً تكنولوجيا: علم التطبيق. وهي التطبيق المنظم لمجموعةٍ من المفاهيم، والمبادئ، وقوانين ونظريات العلم، في بجالات

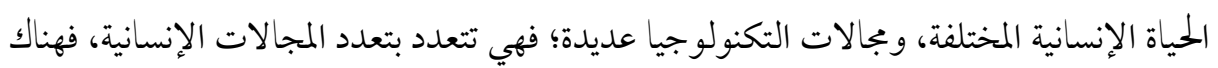
تكنولوجيا الطب، والعلوم الحيوية، والفضاء، والحروب، والاتصالات، والزراعة، والمعلومات، و التعليم. فيما يعد تكنولو جيا التعليم بأنها "تطبيقات العلم لحل المشاكل العلمية أي: معالجة النظريات

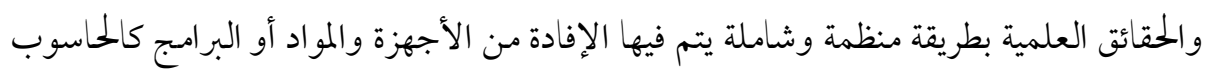
والتلفاز التعليمي والبرامج التشغيلية ويطلق عليها " تقنيات التعليم (الأبرط، II ـ ب، ص: ع ع). مفهوم تكنولوجيا التعليم: من التعريف العام لمصطلح تكنولوجيا، يمكن تعريف تكنولوجيا التعليم بمجموعةٍ من التعريفات منها: دراسة الكيفية التي يتم فيها وضع المعرفة العلمية، واستخدامها بشكلٍ عملي؛ لتوفير ضروريات

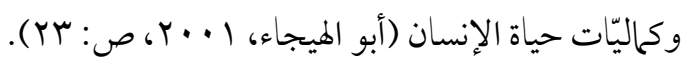


إطارُ فكري، ومنهجيةٌ في العمل، وأسلوب لحل المشكلات، يستند علن النُّمُم الفعّالة، لتحقيق

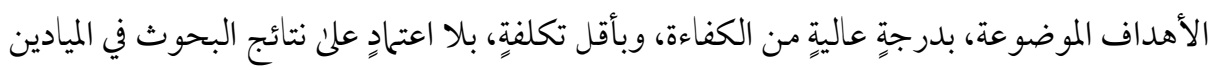

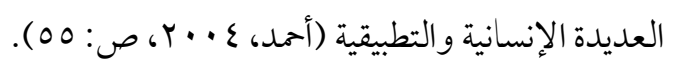

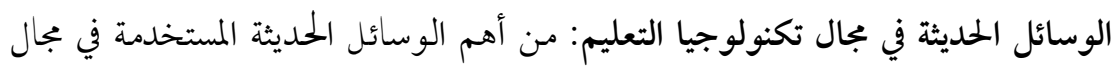

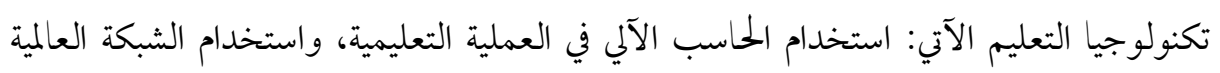

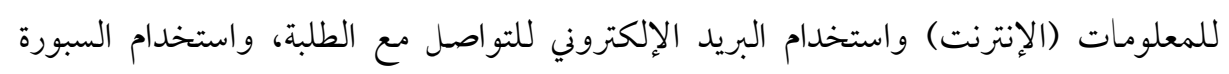

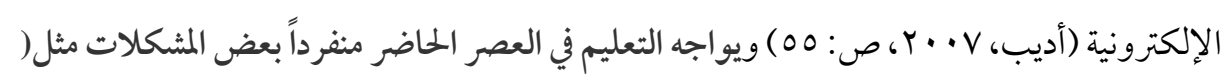

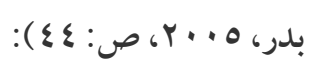
مكونات تكنولوجيا التعليم كنظام: أي نظام يتكون من مدخلات وعمليات داخلية وخرجات، ويمكن أن تتمثل تكنولوجيا التعليم كنظام فيا يلي:

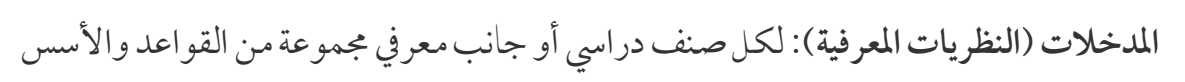

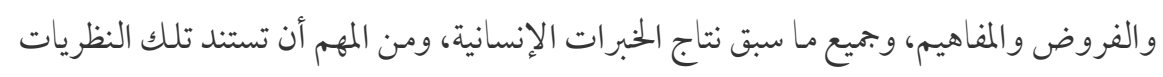

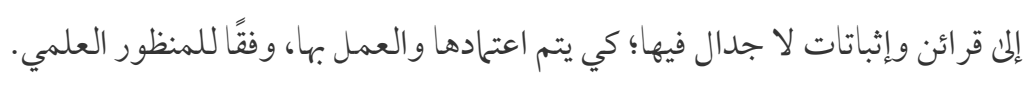

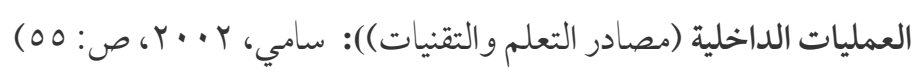

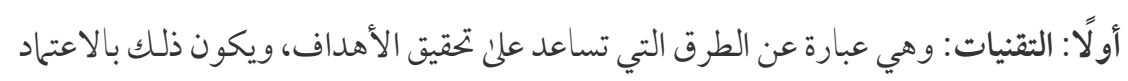

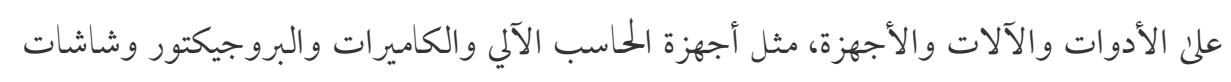
العرض، وكل ما يستجد من تقنيات.

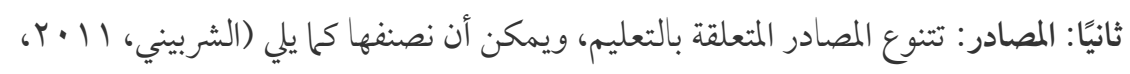
ص:TYY):

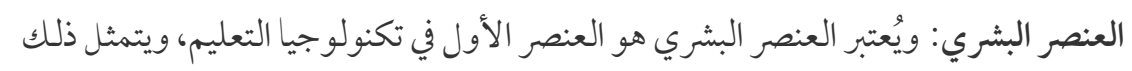

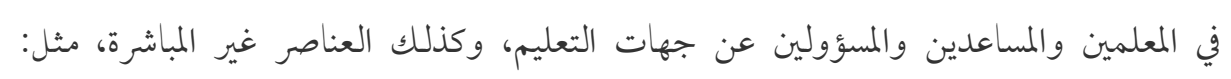
العسكريين والشرطيين والمهندسين والأطبَّاء... إلخ. 
المثاكل والمعوقات التي تواجه استخدام تكنولوجيا التعليم وكيف يمكن التغلب عليها: تطبيق أو استخدام تكنولوجيا التعليم قد يو اجه بكثير من المشاكل و المعوقات، ومن أبرزها ما يلي: ا. عدم توافر الماديات لجلب التقنيات المناسبة: في طليعة معوقات استخدام تكنولوجيا التعليم عدم وجود موارد مادية كافية؛ لجلب الأجهزة والمعدات، والتي تساهم في خلق بيئة تعليمية عصرية، وهو ما يظهر جليَّا في الفروقات بين الدول النامية والدول المتقدمة.

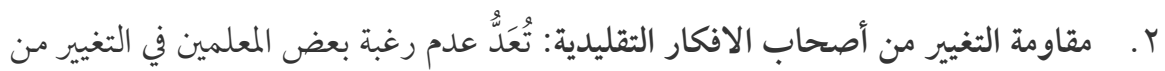
بين أبرز المشاكل والمعوقات، حيث إن البعض يفضل البقاء والاستمرار علن الوضع

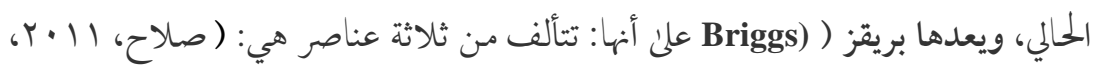
ص: ع ): الأدوات والأجهزة والبرمجيات المستخدمة في العملية التعليمية، وتفاعل

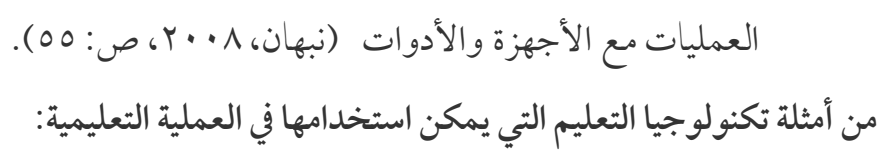
Smart الـ السبورة الذكية (السبورة التفاعلية : SMART Boards) تعد السبورات الذكية Board من اللوحات، أو السبورات التفاعلية البيضاء كبيرة المساحة، والحساسة للمس، ويتم استخدامها لعرض ما على شاشة الكمبيوتر، من تطبيقات، ومصادر تعليمية متنوعة، وتستخدم السبورات الذكية في الفصول الدراسية، وقاعات المحاضرات، والاجتماعات، والمؤتمرات، والندوات، وورش العمل، وتستخدم في والتواصل من خلال الإنترنت، ويمكن توصيلها بالكمبيوتر، وجهاز العرض الرقمي (عبد الحميد، • ( + r، ص: VV). r. Social Media: يمكن استخدام شبكات التو اصل الاجتحاعي مثل فيسبوك Facebook لعمل مجموعة Group عليه خاصة بالفصل الدراسي ليتم من خلاله التواصل بين المدرس والطلاب. 
فيمكن للمدرس أن ينشر علن هذه المجموعة المقالات المثيرة للاهتحام الموجودة في أنحاء الإنترنت المختلفة، جنبا إلن جنب مع تحديثات الفصول الدراسية، والتو اصل مع أولياء الأمور وتقديم

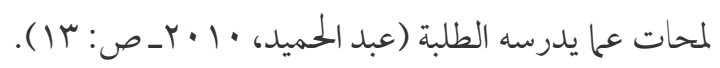
r. البريد الإلكتروني، ورسائل شبكات التواصل الاجتحاعي: Email \& Social Media Messaging الطلبة خارب الفصول الدراسية لتناول المزيد من المناقشات بعد ساعات العمل، ويمكن أيضاً - للمعلمين والمحاضرين التواصل مع الطلاب بشكل من خلال عناوين الاتصال الخاصة بشبكات التواصل الاجتماعي لتقليل المخاوف التي قد تجعل الطلاب لا يرغبون في

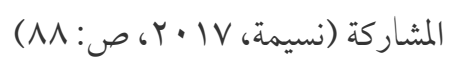

ع. جهاز عارض البيانات: بدأ استخدام جهاز عرض البيانات حديثًا في المؤسسات التعليمية،

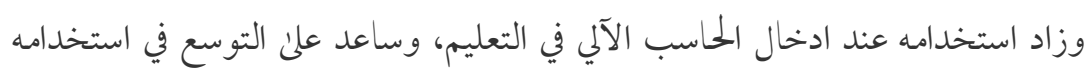

$$
\text { تناقص سعره، وزيادة كفاءة العرض. }
$$

معوقات توظيف المعلم لمفاهيم ومهارات تكنولوجيا التعليم داخل الفصل: ولكن تلك الأهداف سابقة الذكر تعترض تحقيقها بعض المعوقات حيث تشير العديد من البحوث إلى أن أغلب المعلمين لا يقدرون علن استخدام تكنولوجيا التعليم في قاعات الدرس، بسبب عدم إلمامهم

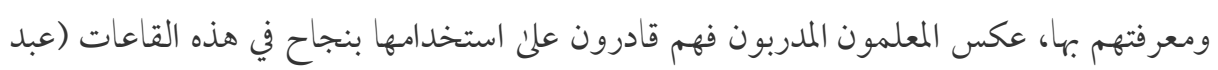

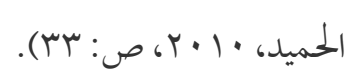

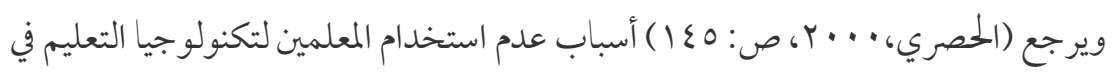

العملية التعليمية إلى أن كثير من المعلمين غير مدربين علن استخدامها ولا توجد لديهم القناعة بدورها وأن بيئة الفصل وبيئة المدرسة غير مهيأة لاستخدام هذه التكنولوجيا. 
ويؤكد (خميس، 997 (19 ص ص ع () ذلك بقوله أن: معوقات استخدام تكنولوجيا التعليم في العملية التعليمية يرجع لندرة برامج التدريب للمعلمين أثناء الخدمة في مجالات تكنولوجيا التعليم

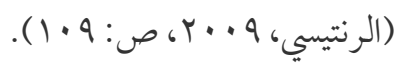

تكنولوجيا التعليم مهنة: ترتبط بالأفراد الذين يتعاملون مع تكنولوجيا التعليم، منهم أخصائي تكنولو جيا التعليم، الفني والمساعد، وهناك المصمه التعليمي، والمبرمج والمخطط التعليمي. يشترط في كل واحد إعداداً مهنياً قائماً على معرفة ودراية بمكونات تكنولو وجيا التعليم من إعداد لبرمجيات تعليمية، وتصميم أنشطة تعليمية، وبناء وعرض المادة المعرفية (أبو سمرة، 7 ا ب Y، ص: (1) نشير في الصدد إلى أن المصطلح مر بعدة مراحل تطورية، اختلفت باختلاف الدور الذي

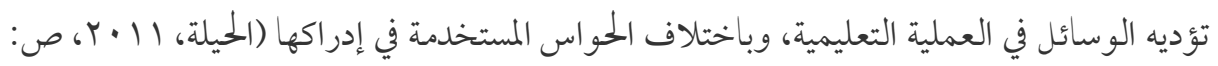

لقد لقي مصطلح الوسائل التعليمية قبو لاً لدئ رجال التربية في مقابل المصطلحات الأخرى'، فهو أكثر شيوعاً وشمولاً عن بقية المسميات التي قصرت في التعبير عن الدور الذي يمكن أن تقوم

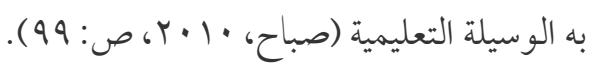
ولعل من بين الأسباب التي حملت علن التداخل بين المصطلحين التقدم العلمي والتقني الهائلين الذين شهدتها العقود الأخيرة في بجال الاتصالات، ومن خلال ظهور أجهزة الحاسب الآلي أيضاً، فقد حدث تداخل بين مفهوم الوسائل التعليمية ومفهوم تقنيات التعلم، حيث استخدم الكثيرون مفهوم تقنيات التعليم كاسم جديد لمفهوم الوسائل التعليمية، وذلك لعدم الفهم الواضح

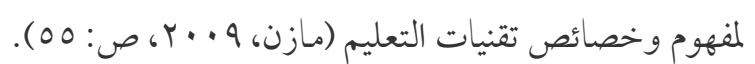
وكذا النظرة القاصرة إلى تقنيات التعليم علن أنها الأجهزة الإلكترونية والمستحدثات التقنية

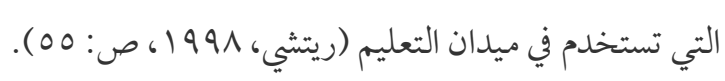


أسس ومرتكزات تكنولوجيا التعليم: برزت وبشكل واضح علن الساحة التعليمية بصفة عامة، وتعليم العلوم الإنسانية بصفة خاصة مشكلات تعليمية عديدة، ومصدرها متباين ومتنوع، فمنها ما كان نتيجة طر ائق التعليم غير المجدية التي أصبحت لا تخدم المعرفة الإنسانية المطلوب نقلها، ومنها ما يتعلق بالأداء والمجهود التعليميين، كل هذا ضمن فلك التعليم عاليم عامة. شهد ميدان تكنولوجيا التعليم مجموعة من التحولات والتطورات التي دعمت دور تكنولوجيا التعليم بإنشاء نظم تعليمية بديلة غير تقليدية، حيث تركز على حل الصعوبات التعليمية، فانبنت علن آلية الجمع بين أسلوبي التعليم الجلماعي والتعليم الفردي، حيث يعار الاهتحام أكثر إلى

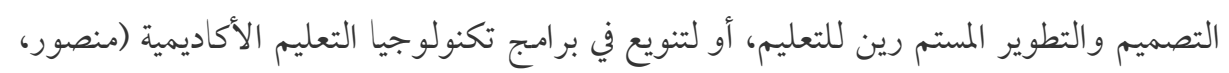

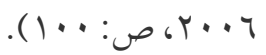

$$
\begin{aligned}
& \text { ومن أهم أسسه ومرتكزاته، ما يلي: }
\end{aligned}
$$

ا ـ يرتبط دور تكنولو جيا التعليم ارتباطاً مباشراً بتطوير عمليتي التعليم والتعلم، حيث الغرض اضل

$$
\text { من حضوره هو القضاء علئ مشكلات التعليم المتنوعة والمتجددة. }
$$

تكنولوجيا التعليم علم أكاديمي قائم علنى آليات التحليل والتفسير والبحث في أسباب حدوث المشكلات التعليمية والعوامل المؤثرة فيها .بالبحث عن الحلول المحتملة المناسبة بعد تفكيك ولك

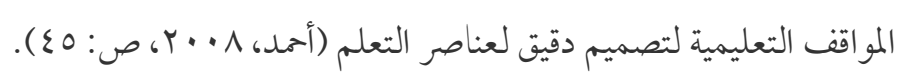

r. تقوم تكنولوجيا التعليم على منطق التفكير العلمي والمنهج التجريبي في تحليل المشكلات

\section{التعليمية.}

r. تكنولوجيا التعليم علم يجمع النظري والتطبيقي، وهذا ما ينتفي في كثير من العلوم أو

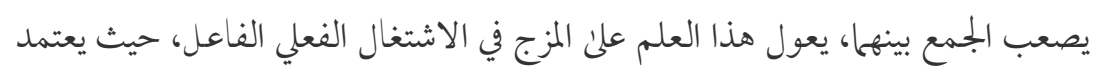

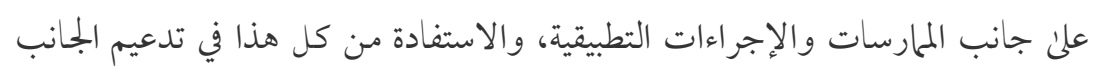

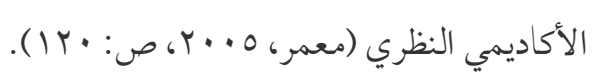


ع. تكنولوجيا التعليم منظومة متكاملة تقوم علن فعل الربط الوظيفي بين مكونات المنظومة التعليمية، للوصول إلى نتائج وحلول تعليمية مؤسسة شاملة تنطبق على الكل لا على حل

$$
\text { جزئي (عنصر من العناصر فقط) بل العملية والموقف التعليميين. }
$$

ه. إن منطلق اشتغال تكنولوجيا التعليم ومشار كاتها في ميدان التعليم، ليس مجرد ملـء الفراغ، أو وضع شكليات، بل إنه قائم علن الهدف العلمي الواضح والمؤسس، فالو اقع التعليمي هي عينة التجريب والعملية التعليمية، والمتعلم هو الذي يخرج في الأخير بالفائدة، فتكنولوجيا التعليم هادفة بناءة واقعية في فلسفتها وتركيبتها .فهي تخضع لمعايير محددة، وهذه الأخيرة عبارة عامة واسعة تصف ما ينبغي أن يكون عليه الشيء، فهو توصيف يشرح

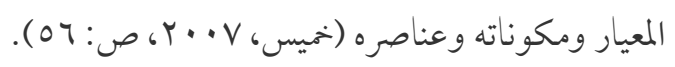$$
\text { الدراسة الميدانية: وتمت كالتالي: - }
$$

منهج الدراسة: استخدمت الدراسة الحالية المنهج الوصفي التحليلي. أدوات الدراسة: فقد استخدمت الدراسة الاستبانة كأداة في بحثها. عينة الدراسة: تم تقسيمها كالآتي ه , ro من الذكور وه , حـ \% أناث. عينة الدراسة وفق السنة الدراسية: بلغ عدد عينة الدراسة الحـالية ا • ا وتم توزيعهاوفق نتائج

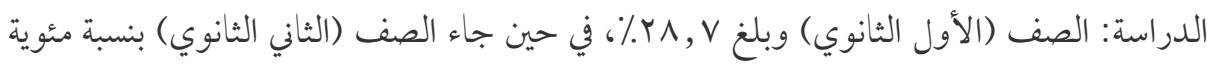

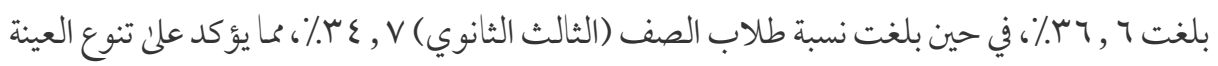
واستخدام تكنولوجيا التعليم في جميع (الصفوف الثانوية) وهذا يؤكد على أهمية استخدام تكنولوجيا التعليم.

عينة الدراسة حسب محل الإقامة: توزيع عينة الدراسة حسب: (محل الإقامة) حيث بلغت نسبة

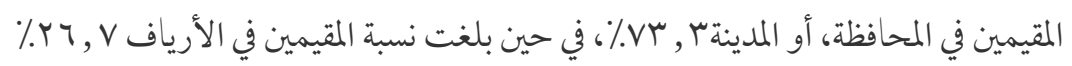
قياس سرعة النت في مكان إقامة الطالب عينة الدراسة الحالية: يتبين من نتائج الدراسة: جاء في الترتيب (الأول) من وجهة نظر عينة الدراسة بالنسبة لسرعة النت (السرعة جيدة) بنسبة مئوية بلغت

\section{http://dx.doi.org/10.29009/ijres.4.1.7}




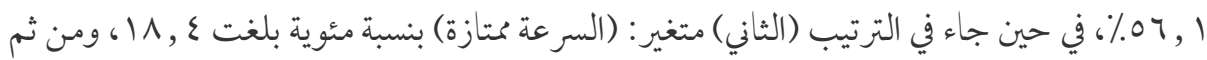
جاء في الترتيب (الآخير) متغير: (بطيء جداً) بنسبة مئوية بلغت ؟ , • (٪، ويمكن تفسير ذلك بأن: هناك اتفاقًاً ورضاً من قبل أفراد العينة عن خدمة الإنترنت وأنها تلبي احتياجاتهم الشخصية والعلمية. اسدخدامات عينة الدراسة للتطبيقات التعليمية ومواقع الانترنت وقذوات عين في العملية التعليمية: اتضح من نتائج الدراسة، ما يلي: جاء بالنسبة لعينة الدراسة من حيث مستوي استخدام العينة للتطبيقات التعليمية ومواقع الإنترنت وقنوات عين في العملية التعليمية، جاء في الترتيب (الأول)

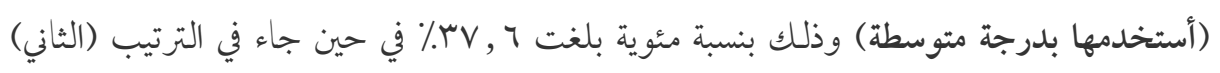

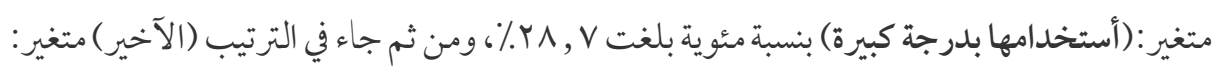
(لا أستخدامها مطلقاً) ويمكن تفسير ذلك بوجود جائحة كورونا وما سبيته من عدم مو اصلة العملية التعليمية بالحضور داخل القاعات التدريسية. وقد أدي ذلك إلى تكثيف استخدام التكنولوجيا من أجل اتمام العملية التعليمية، واستكمال ما تم قطعه من مناهج عن طريق المو اقع والتطبيقات والقنو ات التعليمية المتخصصة، لذا يمكن القول بأن تكنولوجيا التعليم ضرورة حتمية بالمناهج والمدارس والإدارات التعليمية المختلفة لا غني عنها في العملية التعليمية. المدة الزمنية لاستخدام عينة الدراسة للإنترنت التعليمي في وجود فيروس كورونا: اتضح من نتائج الدراسة، ما يلي: جاء في الترتيب (الأول) بالنسبة للفترة الزمنية التي تستغرقها عينة الدراسة في

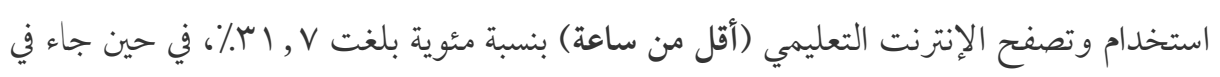

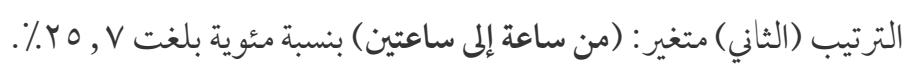

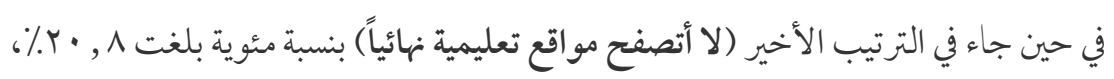
وبناء علن ما تم عرضه يمكن القول بأن جميع أفراد عينة الدراسة يستخدمون الإنترنت التعليمي في

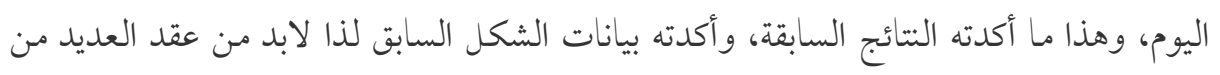
الدورات للطلاب عن كيفية استخدام المواقع. 
أهم الأجهزة الحديثة التي يتم من خلالما تصفح الإنترنت من قيل عينة الدراسة الحالية. اتضح من نتائج الدراسة، ما يلي: جاء في الترتيب (الأول) بالنسبة للأجهزة الحديثة التي يتم من خلالها تصفح الإنترنت من قبل عينة الدراسة (المويايل والجوال) بنسبة مئوية بلغت ا ,^9٪٪. بينما جاء في الترتيب (الثاني) متغير: (اللاب توب) بنسبة مئوية بلغت ا ر بـع٪، في حين جاء في الترتيب (الأخير) متغير: (لا أملك جهاز) بنسبة مئوية بلغت 9 , ٪٪، مما سبق عرضه تري الدراسة أن غالبية أفر اد العينة يستخدمون الاجهزة الحديثة في تصفح الإنترنت والمواقع التعليمية كما تؤكد النتائج السابقة على أهمية الاجهزة الحديثة في تصفح الإنترنت التعليمي. أهداف ودوافع تصفح عينة الدراسة لتصفح الإنترنت: اتضح من نتائج الدراسة، ما يلي: جاء في الترتيب (الأول) بالنسبة (لأهداف ودوافع تصفح عينة الدراسة للأنترنت التواصل مع الآخرين)

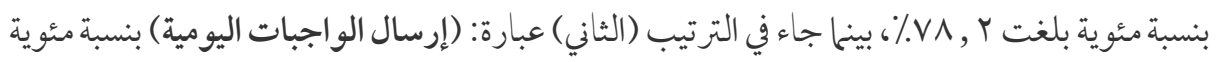

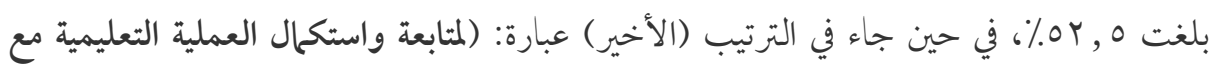

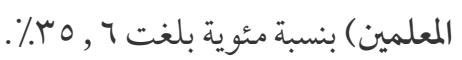
ومما سبق عرضه يمكن القول: أنه مـاز يسيطر علن الأفراد تصفح الإنترنت من أجل التو اصل مع الآخرين والتبادل الاجتحاعي للعلاقات، وهذا يؤكد شيوع وانتشار وكثافة استخدام شبكات

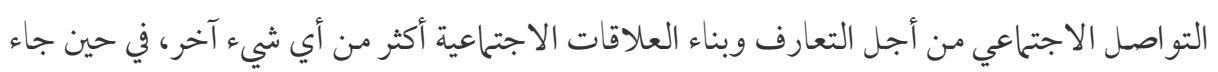
(استكمال العملية التعليمية) في الترتيب (الأخير) حيث لمريعتاد الطلاب علن الفصول الافتراضية، وهذا ما يدعو إلي ضرورة تكثيف الاهتحام بها، وأن تؤلي الدولة والمؤسسات التعليمية الاهتحام بالمنصات والمو اقع التعليمية من أجل التصدي لأي ظروف خاصة مثلم) حدث في جائحة كورونا. رأي الطلاب في مستوي التحصيل العلمي في وجود جائحة كورونا: اتضح من نتائج الدراسة، ما يلي: جاء في الترتيب (الأول) بالنسبة لعبارة (ضعف التحصيل العلمي في أثناء جائحة كورونا بسبب

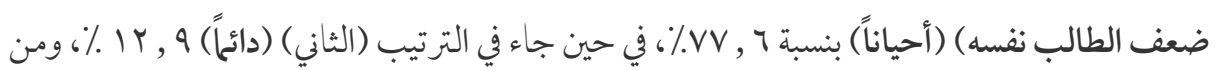
ثم جاء في الترتيب (الأخير) (لا يمكن أبداً) بنسبة مئوية بلغت 9 , 9٪، وبناء على ما سبق تري عينة 
الدراسة: أن جائحة كورونا، ليست هي المسؤولة عن ضعف المستوي العلمي للطالب، ولكن يكمن السبب في ضعف مستوي الطالب العلمي، وليست الآزمة، وما ترتب عليها من تداعيات علمية، متعلقة بالعملية التعليمية. ضعف المستوي العلمي للتحصيل للطلاب و الطالبات بسبب المعلم: اتضح من نتائج الدراسة، ما يلي: عينة الدراسة يرون السبب في ضعف مستوي التحصيل العلمي، يرجع إلي المعلم نفسه، حيث جاءت (أحياناً) في الترتيب (الأول) بنسبة , آح٪ في حين جاء في الترتيب (الثاني) (لا يمكن أبداً)

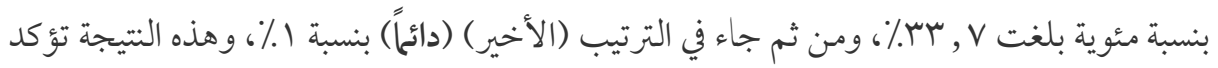
علنا اتفاق عينة الدراسة علن كفاءة المعلم وقيامه بجميع مسؤلياته. التحصيل العلمي للطلاب (الطالبات) ضعيف أثناء جائحة كورونا بسبب البداءٔل التعليمية: اتضح من نتائج الدراسة، ما يلي: جاء في الترتيب (الأول) بالنسبة لضعف التحصيل العلمي للطلاب و الطالبات أثناء جائحة كورونا بسبب البدائل العلمية (أحياناً) بنسبة مئوية ع , الح٪، في حين جاء في

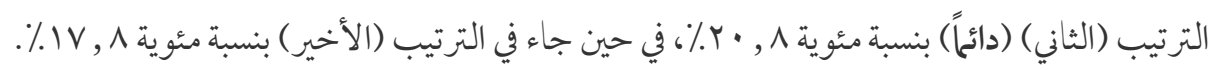
التحصيل العلمي للطلاب (الطالبات) ضعيف أثناء جائحة كورونا بسبب الأسرة والاهتمام بكم: اتضح من نتائج الدراسة، ما يلي: جاء في الترتيب (الأول) بالنسبة لمستوي التحصيل العلمي

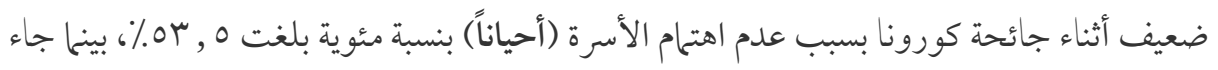

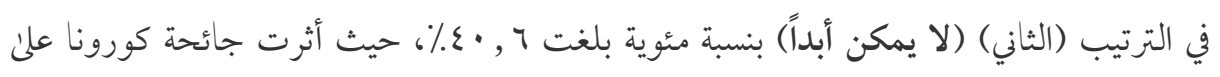
اهتمامتهم حيث أثرت جائحة كورونا وما سببته من تداعيات خاصة بالعملية التعليمية، وذلك يؤكد على اهتحام الأسرة بصحة الأبناء أكثر من التعليم. انخفاض دافعية التعليم لدي الطلاب في ظل جائحة كورونا: اتضح من نتائج الدراسة، ما يلي: جاء في الترتيب (الأول) بالنسبة لعبارة انخفاض دافعية التعليم لدي الطلاب (أحياناً) في الترتيب

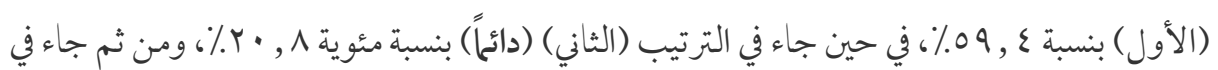


الترتيب (الأخير) (تنخفض) 19 19 1\%، وذلك يؤكد علن التأثيرات السلبية التي سبتها جائحة كورونا وتداعياتها النفسية مما آثر على مستوي التعليم ودافعية التعليم والإنجاز لديهم في ظل جائحة كورونا. كثرة الأعباء على الطلاب، أو الطالبات من قبل البيت والمدرسة أثناء جائحة كورونا: اتضح من نتائج الدراسة، ما يلي: أن من أسباب ضعف التحصيل العلمي لدي الطلاب في جائحة كورونا بسبب كثرة الأعباء علن الطلاب والطالبات من قبل البيت والمدرسة حيث جاء في الترتيب (الأول)

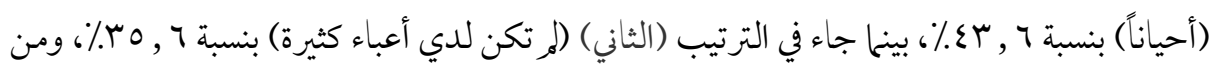

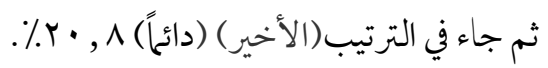
يتضح مما سبق: أن وجود الأعباء لريكن له تأثير على المستوي العلمي للطلبة والطالبات لذا

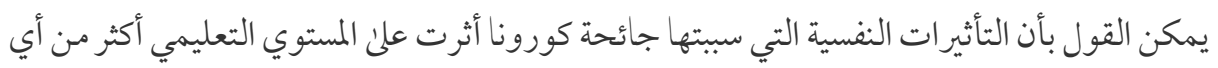
عقبات آخري.

رأي الطلاب والطالبات في عدم قدرة المعلم على استخدام التكنولوجيا: اتضح من نتائج الدراسة، ما يلي: جاء في الترتيب (الأول) بالنسبة لعبارة عدم قدرة المعلم علن استخدام التكنولوجيا

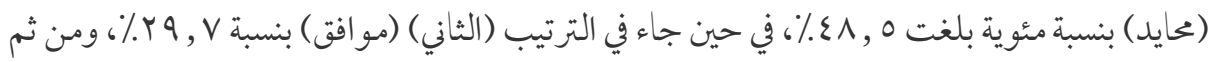

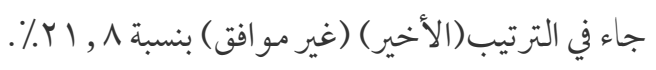
رأي عينة الدراسة في عبارة قلة توافر الأعداد الكافية من المعلمين والمعلمات، المسدخدمين، والمستخدمات للتكذولوجيا:اتضح من نتائج الدراسة، ما يلي:جاء في الترتيب (الأول) بالنسبة لعبارة قلة تو افر الأعداد الكافية من المعلدين، أو المعلمات، و الدسدتخدمين، أو المسخدمات للدكذولوجيا (محايد

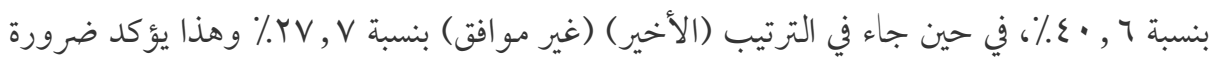
الاهتحام بتوفير التقنيات والتكنولوجيا التي تساهم في تطوير المقررات وكذلك تحسين العملية التعليمية لدي الطلاب خاصة في وجود جائحة كورونا، وما سببته من صعوبات ي العملية التعليمة، وأثر ذلك علئ المستوي العلمي و التحصيلي للطلاب. 
رأي عينة الدراسة في مساهمة الوسائل التكذولوجية التي يعدها المعلم، أو المعلمة في رفع

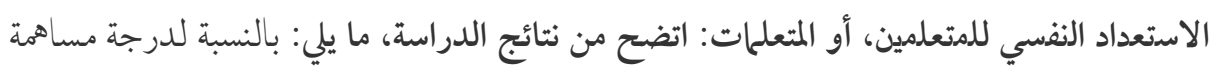

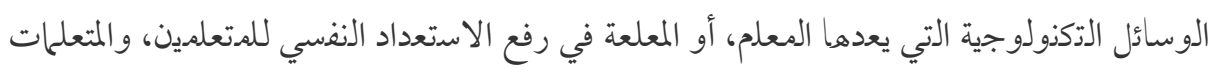

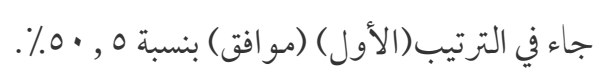

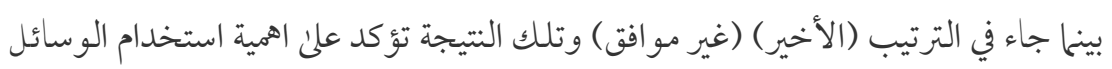

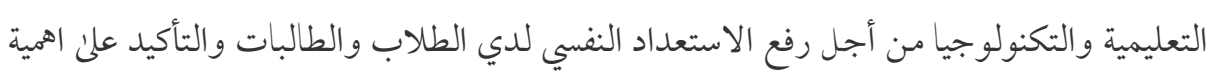
هذه الوسائل في العملية التعليمية والاستعداد للتعليم. يتمكن المعلم، أو المعلمة من استخدام المذصات التعليمية (بوابة المستقبل - مذظومة التعليم الموحد - فنوات عين) في شرح الدروس بإتقان: اتضح من نتائج الدراسة، ما يلي: تفوق المعلم

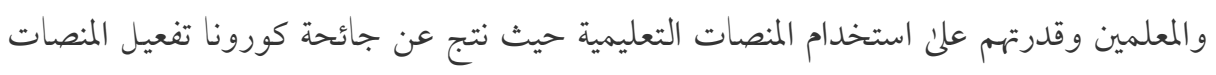

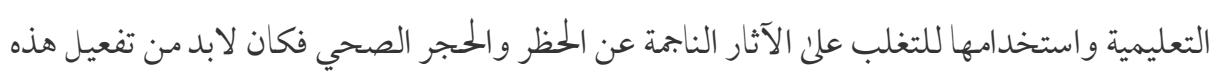

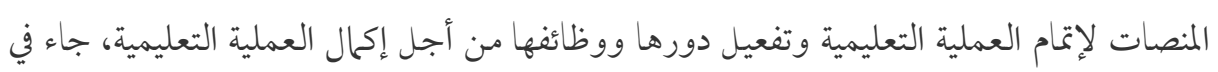

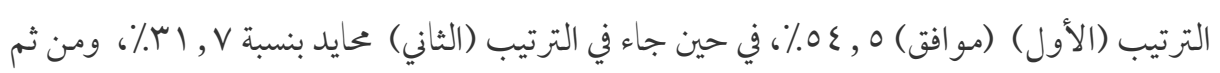

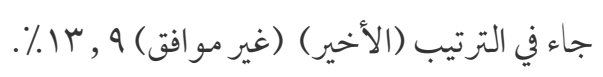

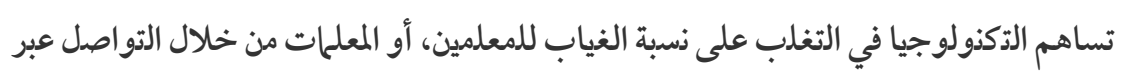

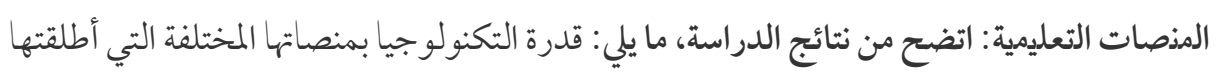

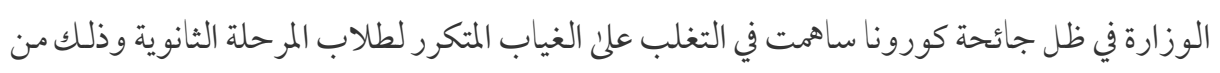
وجهة نظر الطلاب حيث جاء في الترتيب (الأول) (موافق) ع , آح٪ا، في حين جاء في الترتيب (الثاني)

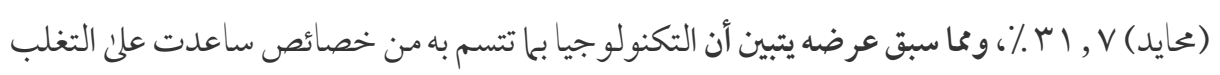
علن مشكلة الغياب من خلال الفصول الافتراضية والتطبيقات المختلفة.

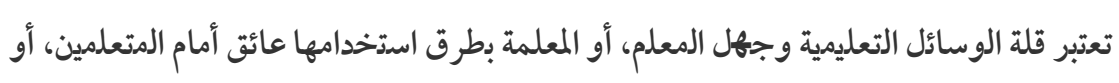

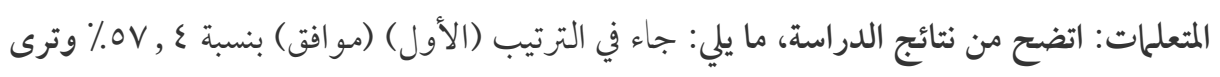


عينة الدراسة: أن قلة الوسائل التعليمية تعتبر عائق أمام المتعلمين، وذلك لأن الوسائل التعليمية تساهم

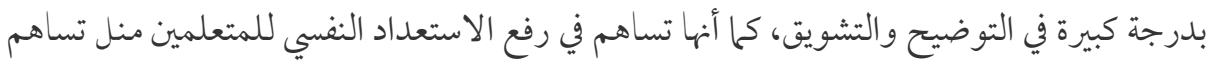

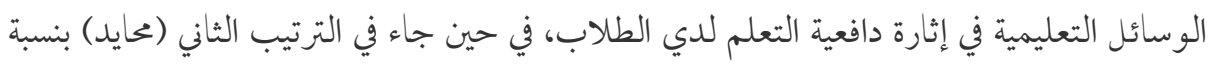
$\% r q, \vee$

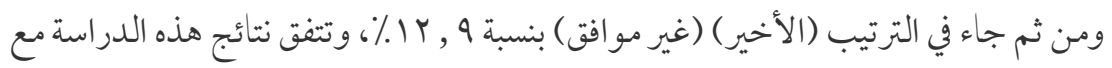

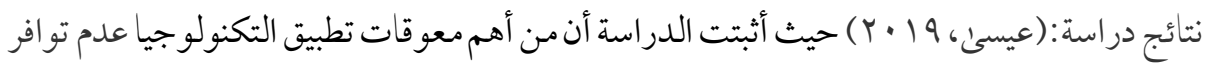

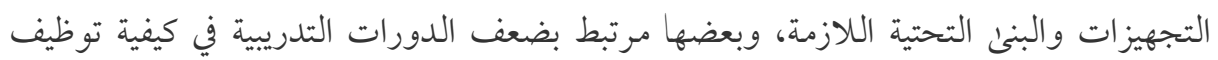
تكنولوجيا التعليم الحديثة في التدريس.

تساعدني التكذولوجيا في معرفة مواعيد الحصص والإعلى الإعلانات الهامة: اتضح من نتائج الدراسة،

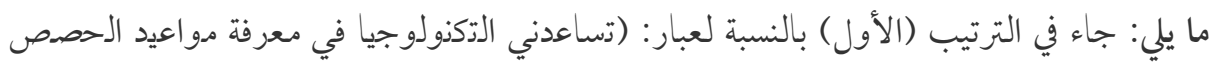

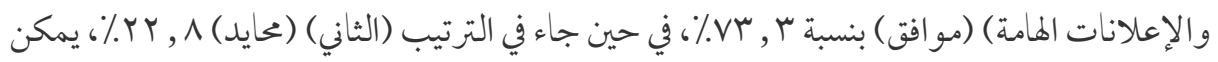

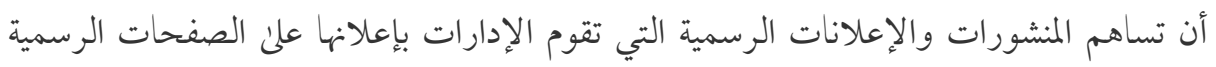
للمدارس في تعريف الطلاب بالمواعيد الهمة.

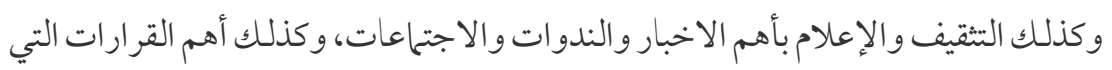

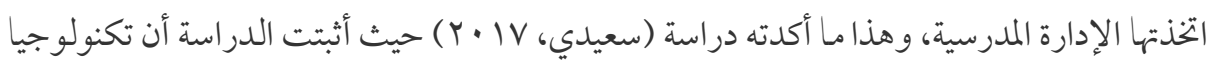

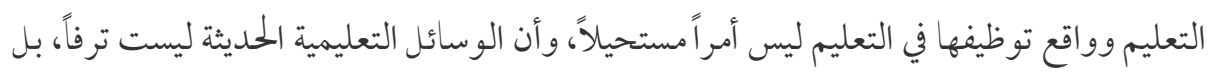
هي ضرورة من ضروريات في العملية التعليمية.

رأي الطلاب في عبارة تساعدني التكنولوجيا في التواصل مع المعلمين، أو المعلمات بالمدرسة:

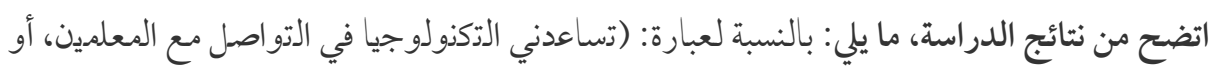

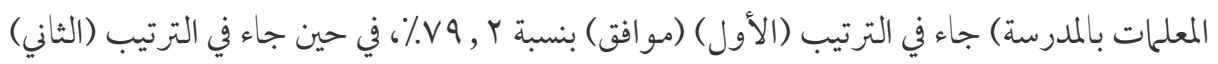

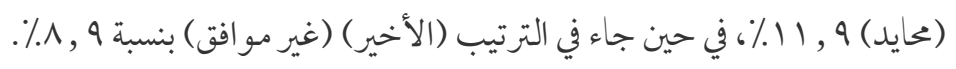

http://dx.doi.org/10.29009/ijres.4.1.7 
رأي الطلاب عينة الدراسة في عبارة تتيح لي التكذولوجيا أكثر من أداة للمذاكرة والاستيعاب: اتضح من نتائج الدراسة، ما يلي: بالنسبة لر أي الطلاب عينة الدراسة في عبارة: (تديح لي التكذولوجيا

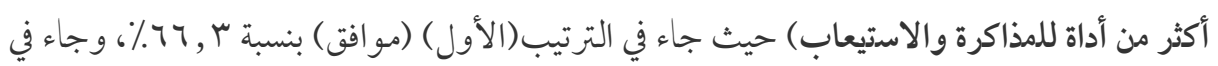

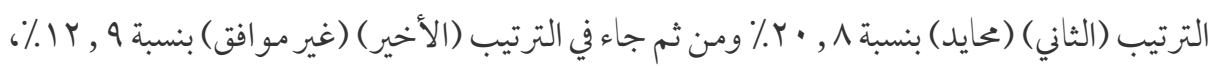
حيث تمتاز التكنولو جيا بتعدد وسائطها وأنماطها واستخدامها أكثر من شكل ونمط يثير دافعية المتعلمين واستقبالهم المعلومة بأكثر من وسيط.

رأي الطلاب عينة الدراسة أتمكن من خلال التكذولوجيا القيام بجميع واجباتي الدذزلية: اتضح من نتائج الدراسة، ما يلي: رأي الطلاب عينة الدراسة: (أتدكن من خلال التكذولوجيا القيام بجميع

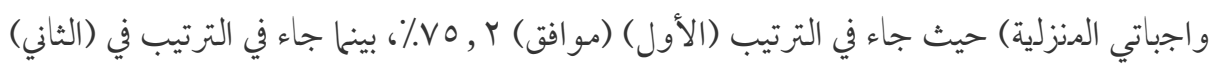

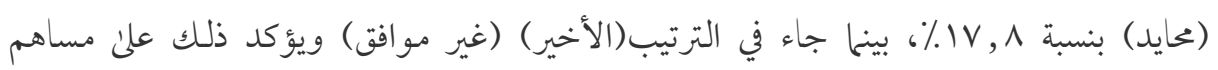

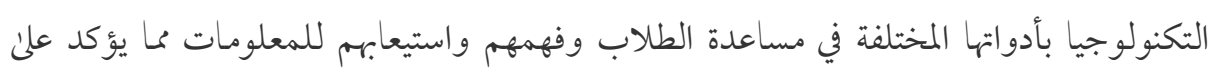
ضرورة الاهتحام بالتكنولوجيا وتدريسها بالجامعات والاقسام المختلفة كذلك بالمدارس لتوظيفها بطريقة صحيحة وسليمة. عبارة تمذحني التكذولوجيا العديد من الخيارات للتغلب على الفروق الفردية لدي: اتضح من نتائج الدراسة، ما يلي: بالنسبة لعبارة تمذحني التكذولو جيا العديد من الخيارات للتغلب على الفروق الفردية لدىل جاء في الترتيب (الأول) (مو افق) بنسبة ع , بح٪، في حين جاء في الترتيب (الثاني) (محايد)

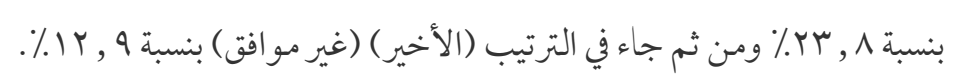

رأي الطلاب في عبارة أسدطيع مناقشة جميع مشكلاتي المتعلقة بفهم الدروس من خلال المذصات التعليمية: اتضح من نتائج الدراسة، ما يلي: بالنسبة لعبارة أسدطيع مناقشة جميع مشكلاتي

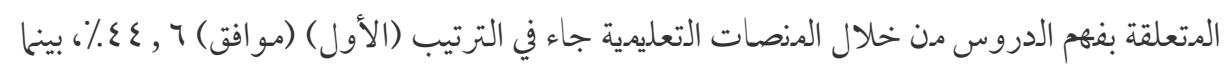

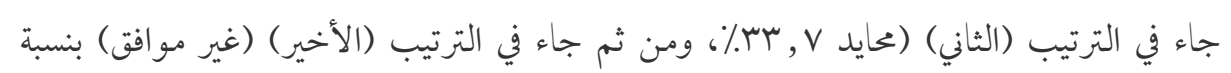
$\%$ \%,$\wedge$ 
درجة استخدام تكذولوجيا التعليم في عمل بذوك للأسئلة وللامدحانات ووالفيديوهات والحقائب التعليمية والواجبات اليومية: اتضح من نتائج الدراسة، ما يلي: بالنسبة لعبارة درجة استخدام تكذولوجيا التعلديم في عمل بذوك للأسئلة ولامتححانات وو الفيديو هات و الحقائب التعليمية و الو اجبات الدومية، جاء في الترتيب (الأول) (موافق) بنسبة ع , rا٪ وجاء في الترتيب (الثاني) (محايد) بنسبة $\%$ \% , V

المذصات التعليمية (بوابة المستقبل - مذظومة التعلدم الموحد - قذوات عين التعليمية) تعبر كافية وتغذيك عن مواقع التواصل الاجدماعي: اتضح من نتائج الدراسة، ما يلي: بالنسبة لعبارة الدذصات التعليمية (بو ابة الدستقبل، مذظومة التعليم الدوحد، قزو ات عين التعليمية تعبر كافية وتغذيك عن مو اقع التو اصل الاجتماعي) جاء في الترتيب (الأول) (إلى حدما) بنسبة ؟ , ^^٪، بينما جاء في الترتيب (الثاني)

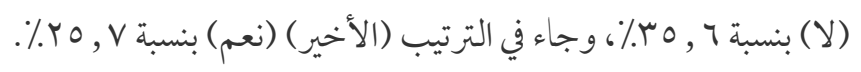
مما سبق عرضه يمكن القول: بأن المنصات التعليمية لا يمكن أن تغني العينة عن مواقع التو اصل الاجتماعي حيث تعتبر مواقع التواصل الاجتماعي جزء من الحياة اليومية للطلاب كما تعتبر وسيلة لتفريغ الشحنات الانفعالية وكذلك الكبت والاحباط ووسيلة أساسية للتعبير عن الرأي

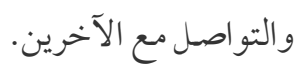
مواقع التواصل الاجتماعي تفضل، أو تفضلين أثناء تعلمك لوحدك عن بعد: اتضح من نتائج الدراسة، ما يلي: بالنسبة لمواقع التواصل الاجتماعي المفضلة في التعليم عن بعد بالنسبة لعينة الدراسة جاء اليوتيوب في الترتيب (الأول) بنسبة بلغت ץ, r بـ٪، في حين جاء في الترتيب (الثاني) (التلجرام)

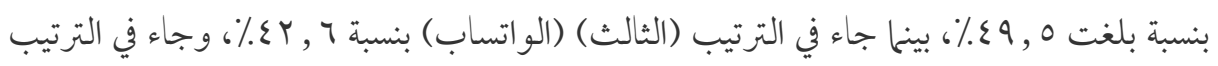

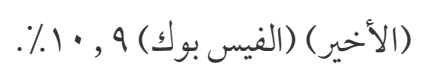

توصيات الدراسة: في ضوء ما سبق عرضه من نتائج يوصي الباحث بالعديد من التوصيات منها: ا ـ ضرورة تفعيل الوسائل التعليمية ومصادر تكنولوجيا التعليم بمدارس التعليم الثانوي. 
r. ضرورة الاهتحام بالمنصات التعليمية لتفعيل دورها في تشر الوعي العلمي واستخدامها في أداء

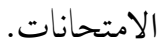

r. ضرورة استخدام تكنولوجيا التعليم للتغلب علن المشكلات الخاصة بالأعداد الكبيرة والتصدي للفروق الفردية الموجودة بين الطلاب. ع. اكساب المعلمين و الطلاب مهارات التعامل مع تكنولوجيا التعليم. ه. تفعيل الدورات والتدريبات المختلفة من أجل إكساب المعلمين المهارات التفاعلية. 
1. الأبرط، نايف علي صالح (1) (1): برنامج تدريبي مقترح قائم علن الكفايات في تقنيات التعليم ودراسة فاعليته في أداء معلمي العلوم دراسة تجريبية في مرحلة التعليم الأساسي بمحافظة ذمار في الجمهورية اليمنية، رسالة دكتوراة في التربية غير منشورة بكلية التربية بجامعة دمشق.

r. ابن منظور (1999 ) ) لسان العرب، دار إحياء التراث العربي، مراجعة وتصحيح: أمين محمد عبد الوهاب، محمد الصادق العبيدي، بيروت، لبنان.

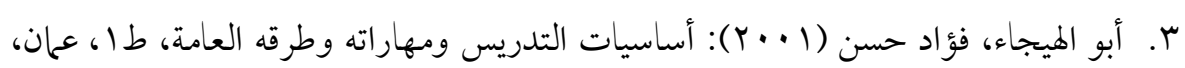

$$
\text { دار المناهج للنشر والتوزيع. }
$$

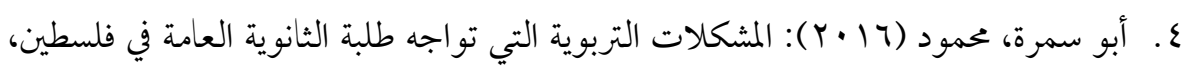
دراسة ميدانية علن طلبة مدارس محافظة رام الله، المجلة الدولية المتخصصة، مججه، عج، ص

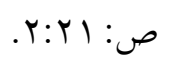

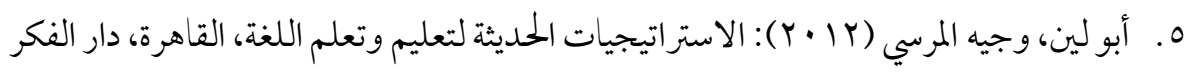

$$
\text { العربي. }
$$

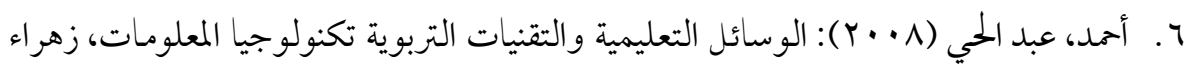

$$
\text { الشرق، القاهرة. }
$$

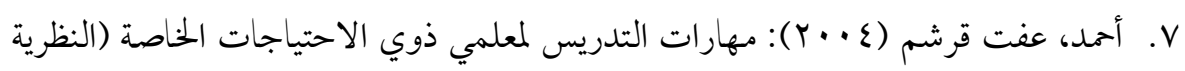

$$
\text { والتطبيق) القاهرة، مركز الكتاب للنشر. }
$$

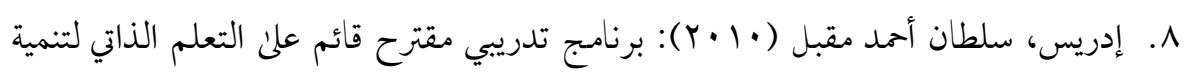
مهارات توظيف مستحدثات تكنولوجيا التعليم لمعلمي المرحلة الثانوية بالجمهورية اليمنية، رسالة دكتوراة غير منشورة، معهد الدراسات التربوية، القاهرة. 


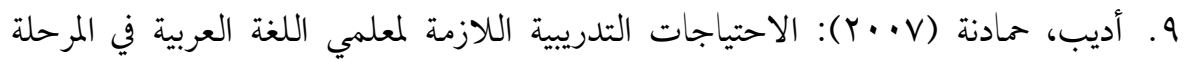
الأساسية كما يقدرها المعلمون في مديريات التربية والتعليم لمحافظة المفرق، الأردن، المجلة

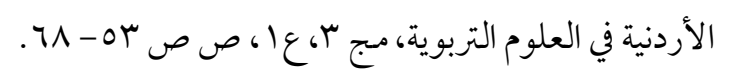

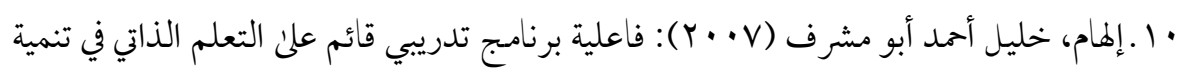

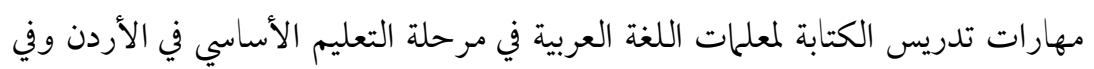
أداء طالباتهن، رسالة دكتوراة غير منشورة، كلية الدراسات التربوية العليا، جامعة عمان

$$
\text { العربية للدراسات العليا، الأردن. }
$$

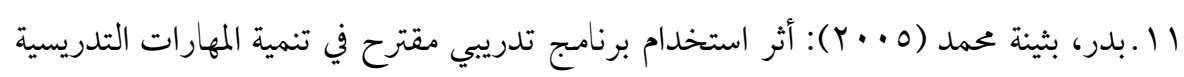
لدئ الطالبات المتعلمات بقسم الرياضيات، في كلية التربية بمكة المكرمة، الجمعية المصرية

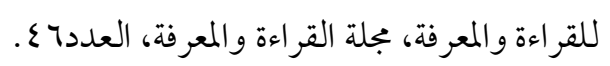

r ا ـالحسن، إبراهيم عبداله (2005): واقع استخدام معامل الحاسب الآلي في تجربة المدارس السعودية الرائدة بمدينة الرياض، رسالة ماجستير غير منشورة، جامعة الملك سعود. با ـالحيلة، محمد محمد (11 • r): أساسيات تصميم وإنتاج الوسائل التعليمية، طا ا، دار المسيرة

$$
\text { لمنشر، عمان، الأردن. }
$$

ع ا.خميس، محمد عطية (V + (Y): الكمبيوتر التعليمي وتكنولوجيا الوسائط المتعددة، طا، دار

$$
\text { السحاب للنشر والتوزيع، القاهرة. }
$$

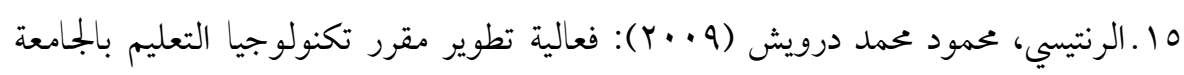
الإسلامية لاكتساب الطلاب المعلمين الكفايات اللازمة في ضوء المعايير المعاصرة، جامعة

$$
\text { الدول العربية، معهد البحوث والدراسات العربية. }
$$

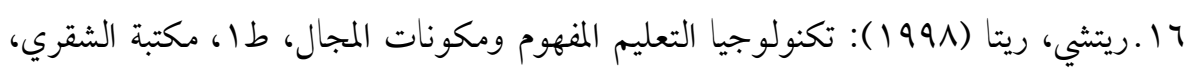

$$
\text { الرياض. }
$$


V ا ـ الزهراني، مريم سعد (• • ( )): واقع استخدام المستحدثات التكنولوجية في خختبرات العلوم بالمرحلة الثانوية من وجهة نظر مشرفات ومعلمات العلوم بمكة المكرمة، رسالة ماجستير

$$
\text { غير منشورة، جامعة أم القرىن. }
$$

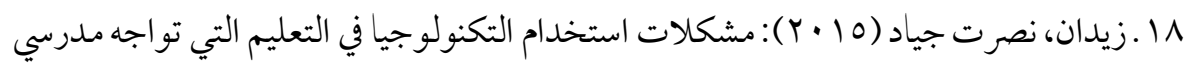
اللغة العربية في المرحلة الإعدادية بمدينة الرمادي العراقية من وجهة نظرهم، رسالة

$$
\text { ماجستير، جامعة الشرق الأوسط، مناهب وطرق تدريس. }
$$

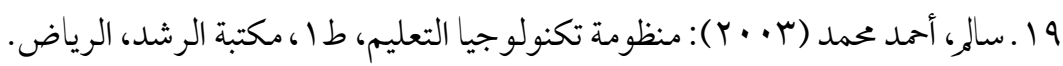

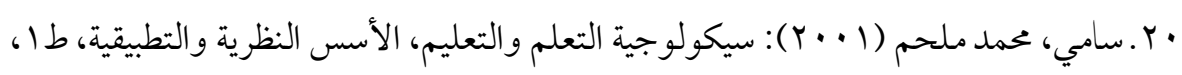

$$
\text { عمان، دار المسيرة للنشر والتوزيع والطباعة. }
$$

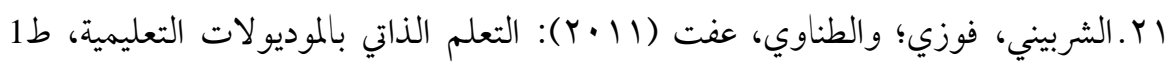

$$
\text { القاهرة، عالم الكتب. }
$$

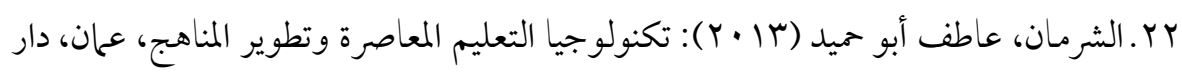

$$
\text { و ائل للنشر. }
$$

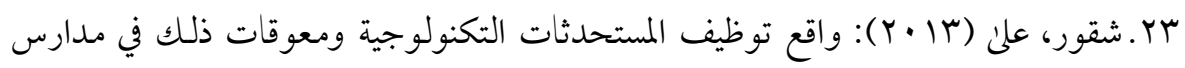
الضفة الغربية وقطاع غزة من وجهة نظر المعلمين، مجلة جامعة النجاح للأبحاث (العلوم

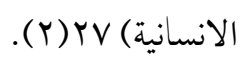

ع r. صباح، محمود ( • • · ): تكنولوجيا الوسائل التعليمية، دار اليازوري للنشر والتوزيع، عمان، الأردن.

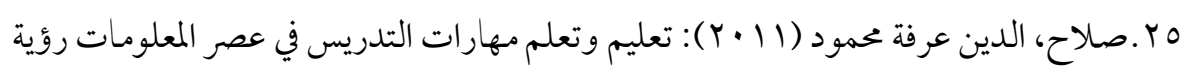
تربوية معاصرة، ط ب، القاهرة، عالم الكتب. 


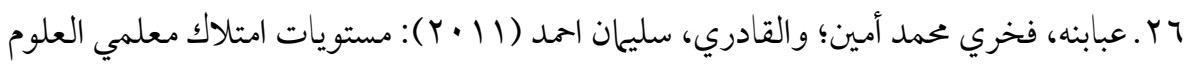

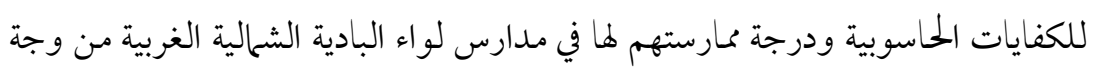

$$
\text { نظرهم و العلاقة بينها، المنارة V| (1) جامعة آل البيت. }
$$

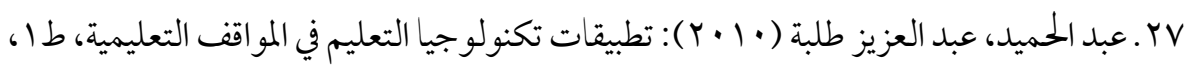

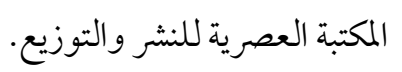

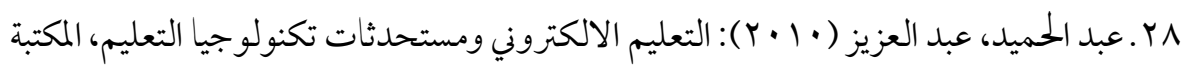

$$
\text { العصرية، مصر. }
$$

q. .عبد اللطيف، محمد (10 · Y): أثر استخدام الحاسوب اللوحي في تدريس وحدة المجسمات لتنمية التصور المكاني والتحصيل في الرياضيات لدئ طلبة الصف الثامن الأساسي، رسالة

$$
\text { ماجستير جامعة اليرموك، الأردن. }
$$

•r.العليات، علي مقبل والقطيش، حسين مشوح (11) (1): معوقات استخدام الحاسوب في تدريس مادة العلوم في المرحلة الأساسية من وجهة نظر معلمي العلوم في البادية الشمالية

$$
\text { والشرقية في الأردن، مجلة جامعة دمشق، مقبول للنشر. }
$$

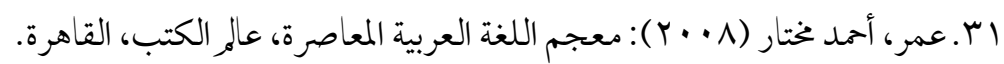

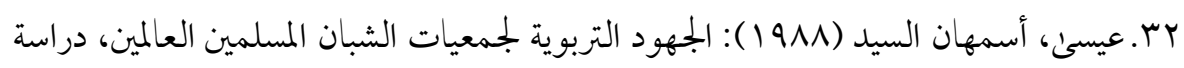
تقويمية، رسالة ماجستير (غير منشورة) كلية التربية، جامعة عين شمس، قسم أصول التربية.

rr.مازن، حسام محمد (q + ·r): تكنولوجيا مصادر التعلم، طا، دار فجر للنشر والتوزيع، القاهرة.

ع r. حمد، ليلن محمد (999 1): المراهقة والتعامل التربوي السوي، المجلة الثقافية، تصدر عن الجامعة الأردنية، نيسان إبريل.

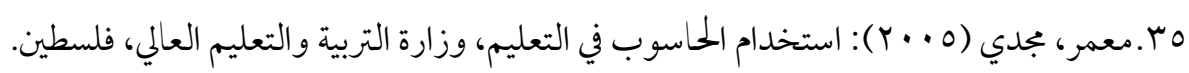


بr.منصور، فرج (Y + ·r): الفجوة الرقمية في المجتمع العربي وأثرها علن اللغة العربية، بجمع اللغة العربية بدمشق، المؤتمر السنوي الخامس، اللغة العربية في عصر المعلوماتية.

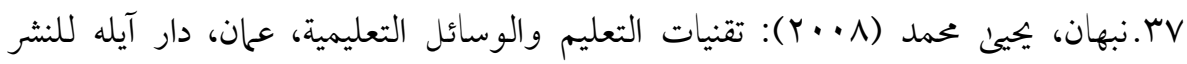
والتوزيع.

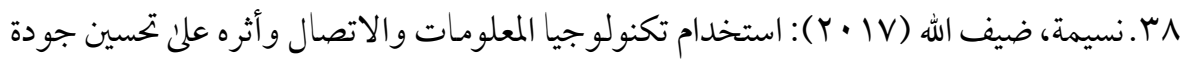
العملية التعليمية، دراسة عينة من الجامعات الجزائرية، رسالة دكتور اةة، الجمهورية الجزائرية الديمقر اطية، علوم التيسير. 
